\title{
Evaluation of Quality and Nutrient Status of Enriched Compost
}

\author{
Manjunatha Chari K, Ravi M. V, \\ Department of Soil Science and Agricultural Chemistry University of Agricultural Sciences, Raichur
}

\begin{abstract}
The disposal of these wastes has been a major concern for the farmers as well as economist. However these wastes contain bio degradable organic and mineral constituents which are of plant origin which can be better utilized for composting. Composting was prepared by chaffed cotton stalks and farm wastes, enrichment with other additives. Enriched compost was prepared using additives like urea, single super phosphate and during the termination of compost zinc, iron, copper and manganese were used. The result reveled that there was a reduction in C:N ratio, reduction in lignin content and total phenol during the composting period compare to original raw material and with increase in other nutrients during the period of composting period.
\end{abstract}

Key words: cotton stalk, enriched, crop residues

\section{Introduction}

India is the largest producer of cotton in the world cultivated in an area of 9.5 million hectare with a production of 30.79 million tonnes of cotton stalks. In Karnataka, it is cultivated in an area of 0.38 million hectare with production of 0.74 million tonnes. Even if $50 \%$ of these residues are utilized as animal feed or fuel, the rest can be mobilized for recycling of plant nutrients and to avoid the dependence on chemical fertilizers to certain extent. The direct addition of crop residues to soil leads to immobilization of plant nutrients which may have adverse effects on the growth of crops. So, prior to this decomposition of organic residues it is essential to avoid immobilization of nitrogen by microorganisms.

Cotton stalks are low in nutritive value and contain higher amount of lignin and cellulose. Though nitrogen and phosphorus is the accepted technology for synthesis of high value composts, incorporation of trace elements in compost preparation not widely attempted. Scientific method of composting using decomposition technique and enrichment can render this waste fit for agricultural use. Because of wider C: N, ratio there will be slow rate of decomposition. Further, inoculation of cellular organism into plant residues will hasten the biodegradation process. To get better quality compost, there is need to enrich cotton stalks with nutrient additives and also by use of microbial culture for proper decomposition.

Enrichment of compost using nitrogen source as urea and crop residues and phosphorus source as single super phosphate and quality of compost was enhanced using micronutrients is less explored so far. It is also possible to use of microbial culture lignin decomposer Phaerocheatae chrysosporium for faster degradation of the resistant material by making use of cow dung. Therefore one should know ideal maturity of compost before application of enriched compost. Various parameters have been proposed to establish the degree of stability and quality of composts. The true maturity assessed by measuring maturity indices such as $\mathrm{C}: \mathrm{N}$ ratio, lignin, phenol content and quantity of secondary and micronutrients during the period of composting.

\section{Materials and methods}

The basic raw materials used for composting were cotton stalks and organic additives were garden weeds, cow dung@ $@ 20 \%$ and urea @ 0.2\%. The inorganic additives were single superphosphate $@\left(\mathrm{P}_{2} \mathrm{O}_{5}\right)$ 1\% and micronutrients (Zn, Fe, Mn and Cu@ 400, 200, 20 and 20 ppm respectively 15 days before termination of composting.).Phanerochaete chrysosporium was used as microbial inoculum @ 1 kg/ton in compost treatments. The samples were collected in four places at different intervals $\left(30^{\text {th }}, 60^{\text {th }}, 90^{\text {th }}\right.$ and $120^{\text {th }}$ days of composting $)$ in each pit and analyzed statistically using CRD. As per the treatments, cotton stalk was spread and compacted well at the bottom of the pit and cultural materials, garden weeds and cow dung slurry were spread over the layer. Over these, mineral additives were added. This procedure was repeated till complete fill up of pit. Turnings were given at a monthly interval up to end of composting $\left(120^{\text {th }}\right.$ days), moisture was maintained around $60-65 \%$. Pre sampling of residues used for this study was done for analysis of chemical properties. Upto $120^{\text {th }}$ days of decomposition, monthly turning of compost samples were collected intermittently, dried and ground to pass through a $1 \mathrm{~mm}$ sieve and used for chemical analysis. Super phosphate with $16 \% \mathrm{P}$ and urea 46 $\% \mathrm{~N}$ and micronutrients sulphates of $\mathrm{Zn}, \mathrm{Fe}, \mathrm{Mn}$ and $\mathrm{Cu}$ were used. Organic carbon $(\mathrm{OC})$ content was determined by dry combustion method by Walkley and Black as described by Jackson (1973), calcium, magnesium and sulphur as described by Jackson (1973), Micro nutrients like zinc, copper, iron and manganese were dteremined by diacid digestion method (Piper, 1966) and analysed by the standard methods and were 
analyzed using AAS and lignin and phenol content estimated by using standard procedure as outlined by Goering and Vansoest. (1975).

Compost treatments involves $\mathrm{C}_{0}$ : Cotton stalk; $\mathrm{C}_{1}$ : Cotton stalk + Cow dung; $\mathrm{C}_{2}$ : Cotton stalk + Cow dung + Microbial culture; $\mathrm{C}_{3}$ : Cotton stalk + Cow dung + Garden weeds; $\mathrm{C}_{4}$ : Cotton stalk + Cow dung + Microbial culture + Garden weeds; $\mathrm{C}_{5}$ : Cotton stalk + Cow dung + Microbial culture + Garden weeds + Superphosphate + urea; $\mathrm{C}_{6}:$ Cotton stalk + Cow dung + Microbial culture + Superphosphate + urea + Micronutrients.

\section{Chemical changes during composting}

\section{C: $\mathbf{N}$}

Irrespective of composting period, there was a significant effect of treatments on $\mathrm{C}$ : $\mathrm{N}$ ratio. All the compost treatments showed decrease in $\mathrm{C}: \mathrm{N}$ ratio with time of decomposition. Lowest $\mathrm{C}$ : $\mathrm{N}$ ratio was recorded in $\mathrm{C}_{6}(12.62 \%)$ and highest in $\mathrm{C}_{0}(63.44 \%)$. However, addition of organic and inorganic additives during composting in $\mathrm{C}_{6}$ recorded lowest $\mathrm{C}: \mathrm{N}$ ratio of $15.97 \%$ and $9.46 \%$ and highest C: $\mathrm{N}$ ratio of $74.00 \%$ and $51.69 \%$ in $\mathrm{C}_{0}$ : Cotton stalk on $30^{\text {th }}$ and $120^{\text {th }}$ day of decomposition respectively. The decrease in $\mathrm{C}$ : $\mathrm{N}$ ratio was due to higher $\mathrm{N}$ content and faster rate of decomposition due to the activity of introduced fungal strain. Several workers have suggested that inoculation of fungal cultures resulted in rapid decomposition with decreases in C: $\mathrm{N}$ ratio (Jagadeesh et al., 1996). It attributed to fungi produce more of cellulase than bacteria.

\section{Calcium and Magnesium}

The significant difference was found in calcium content of the compost treatment at different intervals (Table 2). Higher calcium content of 2.77 per cent recorded in $\mathrm{C}_{6}$ and least in $\mathrm{C}_{0}(0.76 \%)$. However, calcium content of all compost treatments were less at $30^{\text {th }}$ day and there will be no much higher content of calcium recorded at the end of composting period $\left(120^{\text {th }}\right.$ day). There was no significant difference between $\mathrm{C}_{5}$ and $\mathrm{C}_{6}$ mineral enriched treatments but superior over $\left(\mathrm{C}_{0}, \mathrm{C}_{1}, \mathrm{C}_{2}, \mathrm{C}_{3}\right.$ and $\left.\mathrm{C}_{4}\right)$ treatments. The microbial and organic enriched composts along with cotton stalk shows less percent of calcium compared to combination of mineral, microbial and organic enriched compost treatments $\mathrm{C}_{5}$ and $\mathrm{C}_{6}\left(3.18 \%\right.$ and $3.31 \%$ of calcium at $120^{\text {th }}$ day).

Increase in magnesium content with increase in period of composting. However, higher (1.89\%) magnesium content was noticed in $\mathrm{C}_{6}$ and least $(0.37 \%)$ in $\mathrm{C}_{0 .}$. Irrespective of composting period there will be significant effect of treatment on magnesium content. Mineral enriched compost treatments $\mathrm{C}_{5}$ and $\mathrm{C}_{6}$ recorded non significant differences and which is superior over $\mathrm{C}_{0}, \mathrm{C}_{1}, \mathrm{C}_{2}, \mathrm{C}_{3}$ and $\mathrm{C}_{4}$ treatments. Enrichment with superphosphate resulted in higher calcium content. Calcium, sulphur and phosphorus being a constituent of superphosphate and it might have resulted in higher calcium content in mineral enriched compost as compared to $\mathrm{C}_{0}$ : Cotton stalk. Similar trend was observed with respect to magnesium. Higher magnesium content was recorded in $\mathrm{C}_{6}(2.44 \%)$ and $\mathrm{C}_{5}(2.36 \%)$ and least in case of $\mathrm{C}_{0}(0.39 \%)$ at $120^{\text {th }}$ day of composting. Enrichment enhanced the status of these nutrients compared to $\mathrm{C}_{0}$ : Cotton stalk and microbial enriched treatments. Similar results were obtained by Gundappa (1999) and Preethu et al. (2007).

\section{Sulphur}

Sulphur content of cotton stalk residues during the composting period indicates (Table 2) that all the compost treatments were found to have marked influence. Among all the treatments, $\mathrm{C}_{5}$ and $\mathrm{C}_{6}$ recorded highest values $\left(1.13 \%\right.$ and $1.18 \%$ of sulphur at $120^{\text {th }}$ day of composting) and significantly superior over other treatment combinations. Mineral enrichment $\left(\mathrm{C}_{6}\right)$ resulted in higher sulphur content. This was due to sulphur content in super phosphate and also enrichment with micronutrients (Preethu et al., 2007), as these are salts of sulphur resulted in significantly higher sulphur content compared to other treatment combination.

\section{Micronutrients}

With increase in period of composting there will be increase in micronutrient like zinc, iron and manganese content of the compost treatment (Fig.2). Among the compost treatments, the treatment with mineral enrichment shows maximum content followed by other treatment combinations. Among the composts treatment zinc content was high in $\mathrm{C}_{6}$ followed by $\mathrm{C}_{5}$ and least in $\mathrm{C}_{0}$. The treatment $\mathrm{C}_{6}$ recorded highest $(0.044 \%$ and $0.088 \%$ at $30^{\text {th }}$ and $120^{\text {th }}$ day) zinc content which is significantly superior over $\mathrm{C}_{5}$ and other treatment combinations. Iron and manganese content of compost increases with increase in period of composting and at $120^{\text {th }}$ days of maturity $\mathrm{C}_{6}(3.94 \%$ and $0.268 \%)$ and $\mathrm{C}_{5}(3.86 \%$ and $0.256 \%)$ respectively, composts significantly superior over other treatments from $\mathrm{C}_{0}$ to $\mathrm{C}_{4}$.

The changes in the content of lignin, cellulose and hemicelluloses and phenol during composting decreased with composting. This may be due to positive effect of these additives on decomposition by way of increased availability of $\mathrm{N}, \mathrm{P}$ and essential nutrients for microorganisms involved during the decomposition 
process. Microbial succession ensures the breaking down of such compounds over a period of time. The results clearly show that microbial inoculation enhances the degradation of cellulose, lignin and phenols over a period of time. This observation was confirmed by the report of Cortz et al. (1996). According to them cellulose will be decomposed faster than lignin in decomposition system which were rich in cellulose and lignin. Barder and Crowford (1981) reported lignin degradation was greatest in presence of high levels of nitrogen. Further enhancement of lignin degradation occurred in medium containing organic supplemented with low levels of nitrate; this may be reason for high rates of decomposition in $\mathrm{C}_{5}$ and $\mathrm{C}_{6}$. Enrichment through micronutrients showed significant increase in the availability of the compost due to the chelating effect of organic materials. Similar results obtained by Dakshinamurthy and Upendra, 2008 who reported enrichment of zinc and Boron showed increase in availability $\mathrm{Zn}$ and $\mathrm{B}$ content of composting materials this due to organically chelated micronutrients. This is also due to micronutrient enrichment before termination of composting to the compost resulted in increased availability of micronutrients and also due to chelating effect of organic molecules.

\section{Biochemical changes during composting Phenol}

The data on changes in total phenols at different intervals the total phenol content in all the composts decreased with period of decomposition (Fig. 3). Phenol content ranges from $8.00 \mathrm{mg} 100 \mathrm{gm}^{-1}$ in $\mathrm{C}_{0}$ to 26.00 $\mathrm{mg} 100 \mathrm{gm}^{-1}$ in $\mathrm{C}_{1}$ at the $120^{\text {th }}$ days of decomposition. $\mathrm{C}_{5}$ and $\mathrm{C}_{6}$ recorded 16.00 and $16.12 \mathrm{mg} 100 \mathrm{gm}^{-1}$ respectively. Among composts treatment, enrichment with no additives $\mathrm{C}_{0}$ resulted in lower total phenol content compared to organic, mineral and microbial enriched treatments $\mathrm{C}_{1}$ to $\mathrm{C}_{6}$. The highest phenol content was recorded in treatment with all additives viz., garden weeds, superphosphate, urea and microbial culture $\left(\mathrm{C}_{5}\right.$ and $\mathrm{C}_{6}$ ). This may be due to higher humification in presence of adequate nutrients and all additives in enriched composts treatment result in weakening the lignin structure and release of poly phenols. However, amount of humic substances formed during decomposition was higher due to presence of Phanerochaete chrysosporium during decomposition, humic and fulvic acids formed during decomposition of higher lignin containing residues in presence of lignin degrading fungi (Bhattacharya et al., 1999).

\section{Lignin}

The data changes in per cent lignin content in composting material at different intervals that lignin content of decomposing materials decreased with period of decomposing in all the treatments. Among all the treatments, microbial and mineral enriched composts treatment $\mathrm{C}_{6}$ and $\mathrm{C}_{5}$ recorded significantly higher lignin reduction over other treatments $\left(8.03 \%\right.$ and $8.35 \%$ respectively) at $120^{\text {th }}$ as compared to $30^{\text {th }}$ days of composting $\left(12.15 \%\right.$ and $12.28 \%$ respectively) and least lignin degradation was recorded in $\mathrm{C}_{0}\left(18.72 \%\right.$ at $30^{\text {th }}$ and $15.73 \%$ at $120^{\text {th }}$ day) compost treatments (Fig.4). The lignin percent decreased considerably when cotton stalk was taken for composting as compared to their initial status. Among different composts, enriched composts $\mathrm{C}_{5}$ and $\mathrm{C}_{6}$ which received all additives registered lower lignin as compared to other treatments. This might be due to higher decomposition in presence of adequate nutrients and residues undergo biological decomposition. This observation was confirmed by the report of Cortz et al. (1996) which states that cellulose will be decomposed faster than lignin in decomposition system which were rich in cellulose and lignin. Barder and Crowford (1981) reported that lignin degradation was greatest in presence of high levels of nitrogen. Further enhancement of lignin degradation occurred in medium organic supplement with low levels of nitrate; this may be the reason for high rates of decomposition in $\mathrm{C}_{5}$ and $\mathrm{C}_{6}$.

\section{References:}

[1]. Barder M J and Crowford D L 1981. Effects of carbon and nitrogen supplementation on lignin and cellulose decomposition biostreptomyces. Canadian Journal of Microbiology, 27:839-863.

[2]. Bhattacharya, K. K., Saha, N., Mukherjee, N., Bal, R. C., Mandal, S. and Sandhya Das, 1999, Biannual Progress Report of AICRP on microbiological decomposition and recycling of farm \& city wastes, 22-24.

[3]. Cortz J Demard J M Bottner T and Joctur M Monrozier L 1996. Decomposition of medeteranian leaf litter, microcosmos experiment investigating relationship between decomposition rate litter quality. Soil Biology and Biochemistry, 28(4/5): 433-452.

[4]. Dakshinamurthy, K. M. and Upendra Rao. (2008). Effect of organically bound micronutrients on growth and yield of rice, $J$. Ecofriendly Agric., 3(1): 86-87.

[5]. Goering, H. D. and Vansoest, P. J. (1975). Forage fiber analysis, US Department of Agriculture Research Service, Washington.

[6]. Gundappa, G. Kadalli., 1999, Coirdust based enriched compost and characterisation of humic fractions, Ph. D. Thesis, Univ. Agric. Sci., Bangalore (India).

[7]. Jackson M I 1973. Soil Chemical: Prentice Hall (India) Pvt. Ltd., New Delhi.

[8]. Jagadeesh, K. S., Geeta, G. S. and Kulkarni, J. H., 1996, Microbial management of red gram stalk for fuel and fertilizer production. Proceedings of National Seminar on Microorganisms in Sustainable Agriculture, Madurai, p. 100-102.

[9]. Piper, C. S., 1996, Soil and Plant Analysis. Han Publications, Bombay.

[10]. Preethu, D. C., Bhanu prakash, B. N. U. H., Srinivasamurthy, C. A. and Vasanthi, B. G. (2007). Maturity indices as an index to evaluate the quality of compost of coffee blended with other organic wastes, Proc. of the Int. conference on sustain. Solied waste mangement. 5-7, p. 270-275.

[11]. Walkley, A. J. and Black, C. A., 1934, Estimation of soil organic carbon by the chromic and titration method. Soil Sci., 37: 29-38. 
Table 1. Physico-chemical properties of cotton stalk residues used in the study

\begin{tabular}{clc}
\hline Si No. & Properties & Value \\
\hline 1. & pH $(1: 10$ Compost: water) & 5.71 \\
2. & EC $\left(\mathrm{dsm}^{-1}\right)(1: 10$ Compost: water) & 1.43 \\
3. & Organic carbon (\%) & 38.50 \\
4. & Nitrogen (\%) & 0.45 \\
5. & Phosphorus (\%) & 0.20 \\
6. & Potassium (\%) & 0.60 \\
7. & Calcium (\%) & 0.21 \\
8. & Magnesium (\%) & 0.13 \\
9. & Sulphur (\%) & 0.01 \\
10. & Zinc (\%) & 0.012 \\
11. & Iron (\%) & 0.121 \\
12. & Manganese (\%) & 0.038 \\
13. & Lignin (\%) & 19 \\
14. & Cellulose (\%) & 38 \\
15. & Hemicelluloses (\%) & 21 \\
\hline
\end{tabular}

Fig 1: C:N ratio (\%) of different composts at different intervals

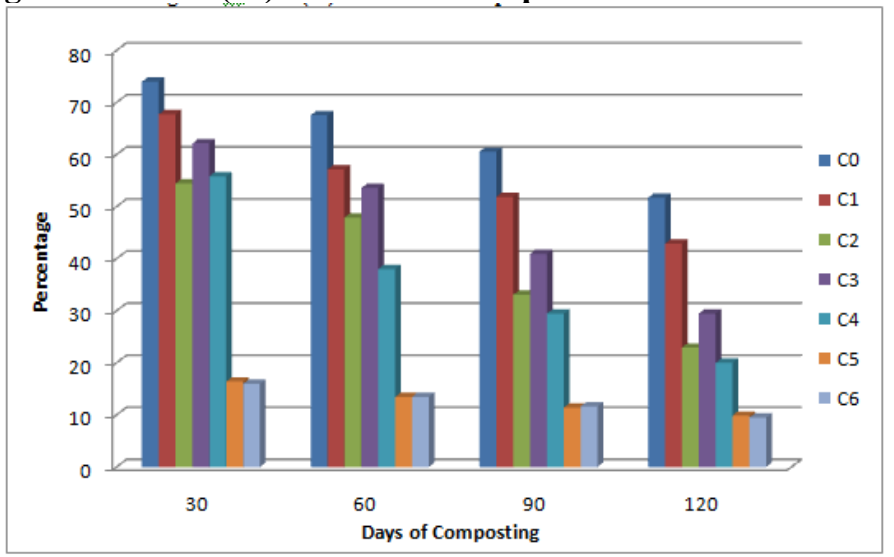

Fig 2: Micronutrient status of different composts at different intervals

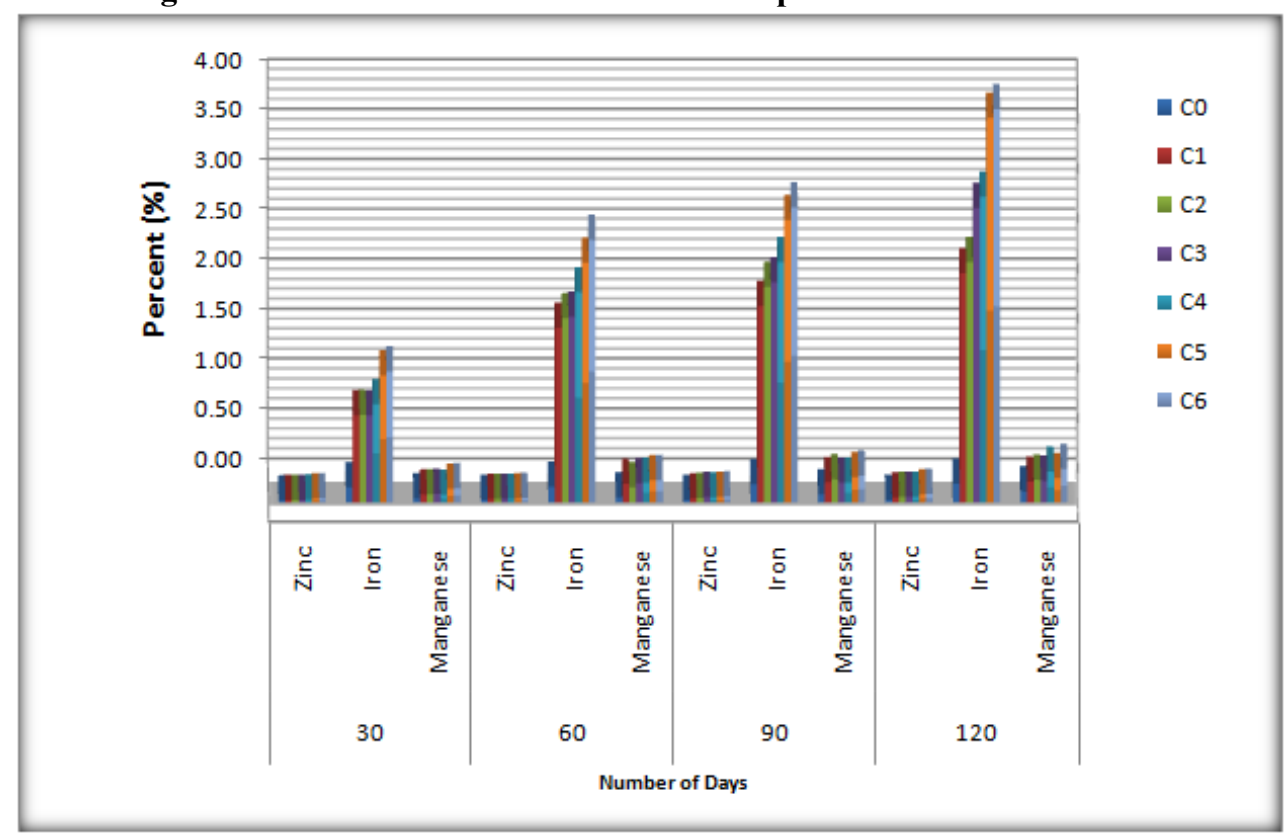


Evaluation of Quality and Nutrient Status of Enriched Compost

Table 2: Nutrient status (\%) of different composts at different intervals of Calcium, Magnesium and Sulphur

\begin{tabular}{|c|c|c|c|c|c|c|c|c|c|c|c|c|}
\hline \multicolumn{13}{|c|}{ suाріли } \\
\hline \multirow{2}{*}{$\begin{array}{l}\text { Intervals } \\
\text { Treatments }\end{array}$} & \multicolumn{3}{|c|}{$30^{\text {th }}$ day } & \multicolumn{3}{|c|}{$60^{\text {th }}$ day } & \multicolumn{3}{|c|}{$90^{\text {th }}$ day } & \multicolumn{3}{|c|}{$120^{\text {th }}$ day } \\
\hline & $\mathrm{Ca}$ & Mg & $\mathbf{S}$ & $\mathrm{Ca}$ & Mg & $\mathbf{S}$ & $\mathrm{Ca}$ & Mg & $\mathbf{S}$ & $\mathbf{C a}$ & Mg & $\mathbf{S}$ \\
\hline $\mathrm{CO}$ & 0.37 & 0.34 & 0.03 & 0.69 & 0.37 & 0.04 & 0.93 & 0.37 & 0.06 & 1.03 & 0.39 & 0.06 \\
\hline C1 & 1.41 & 0.8 & 0.09 & 2.15 & 1.36 & 0.18 & 2.89 & 1.5 & 0.24 & 2.97 & 1.61 & 0.35 \\
\hline $\mathrm{C} 2$ & 1.53 & 0.96 & 0.12 & 2.3 & 1.52 & 0.16 & 2.9 & 1.7 & 0.24 & 3.08 & 1.7 & 0.26 \\
\hline $\mathrm{C3}$ & 1.83 & 1.06 & 0.27 & 2.32 & 1.6 & 0.32 & 2.62 & 1.71 & 0.34 & 2.84 & 1.8 & 0.54 \\
\hline $\mathrm{C} 4$ & 1.5 & 1.24 & 0.25 & 2.34 & 1.68 & 0.34 & 2.44 & 1.75 & 0.35 & 2.79 & 1.86 & 0.71 \\
\hline C5 & 2.27 & 1.35 & 0.86 & 2.57 & 1.84 & 0.94 & 3.1 & 1.92 & 1.35 & 3.18 & 2.36 & 1.4 \\
\hline C6 & 2.27 & 1.36 & 0.86 & 2.65 & 1.79 & 0.99 & 3.17 & 1.95 & 1.41 & 3.31 & 2.44 & 1.48 \\
\hline S.Em \pm & 0.04 & 0.03 & 0.01 & 0.05 & 0.04 & 0.01 & 0.07 & 0.04 & 0.01 & 0.07 & 0.05 & 0.02 \\
\hline CD at $5 \%$ & 0.13 & 0.09 & 0.03 & 0.16 & 0.12 & 0.03 & 0.21 & 0.12 & 0.04 & 0.22 & 0.16 & 0.06 \\
\hline
\end{tabular}

Fig 3: Phenol (mg $\left.100 \mathrm{gm}^{-1}\right)$ at different intervals of composting

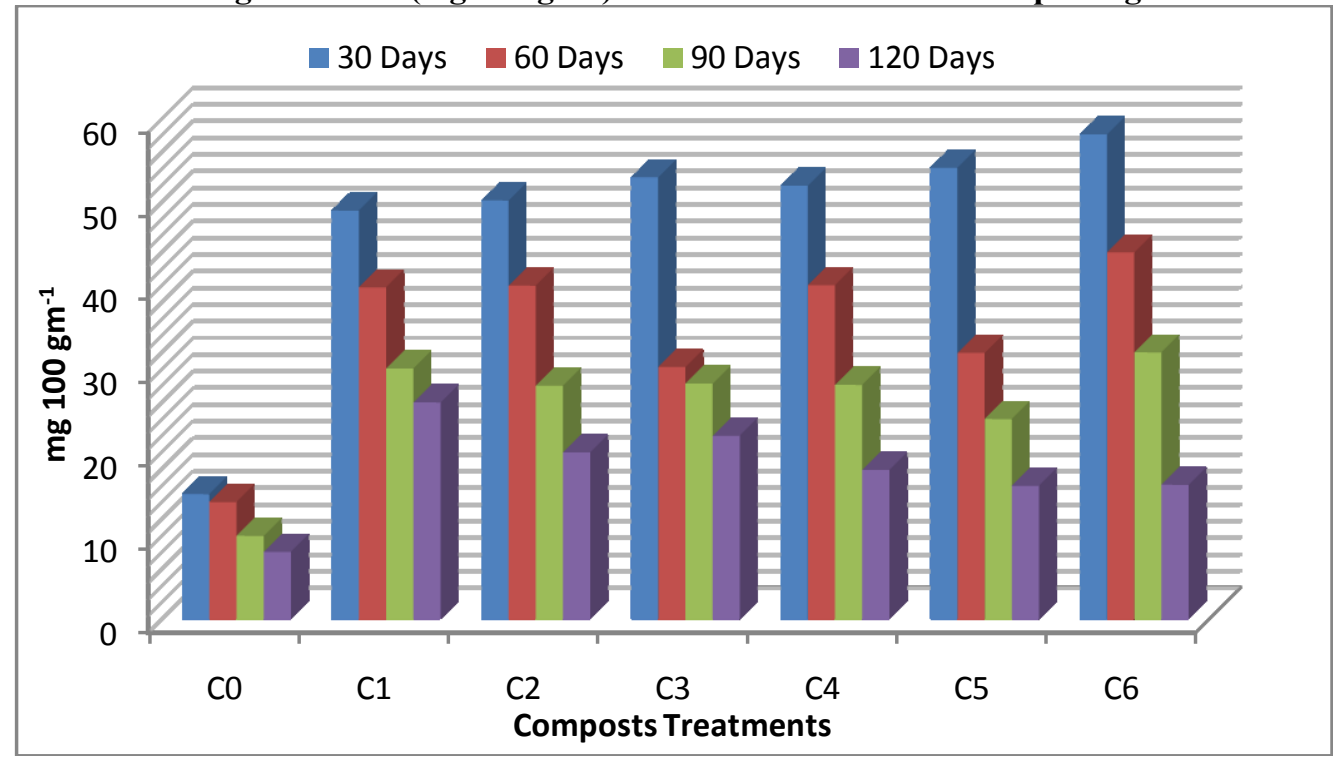

Fig 4: Lignin content $(\%)$ at $30^{\text {th }}$ and $120^{\text {th }}$ days of composting

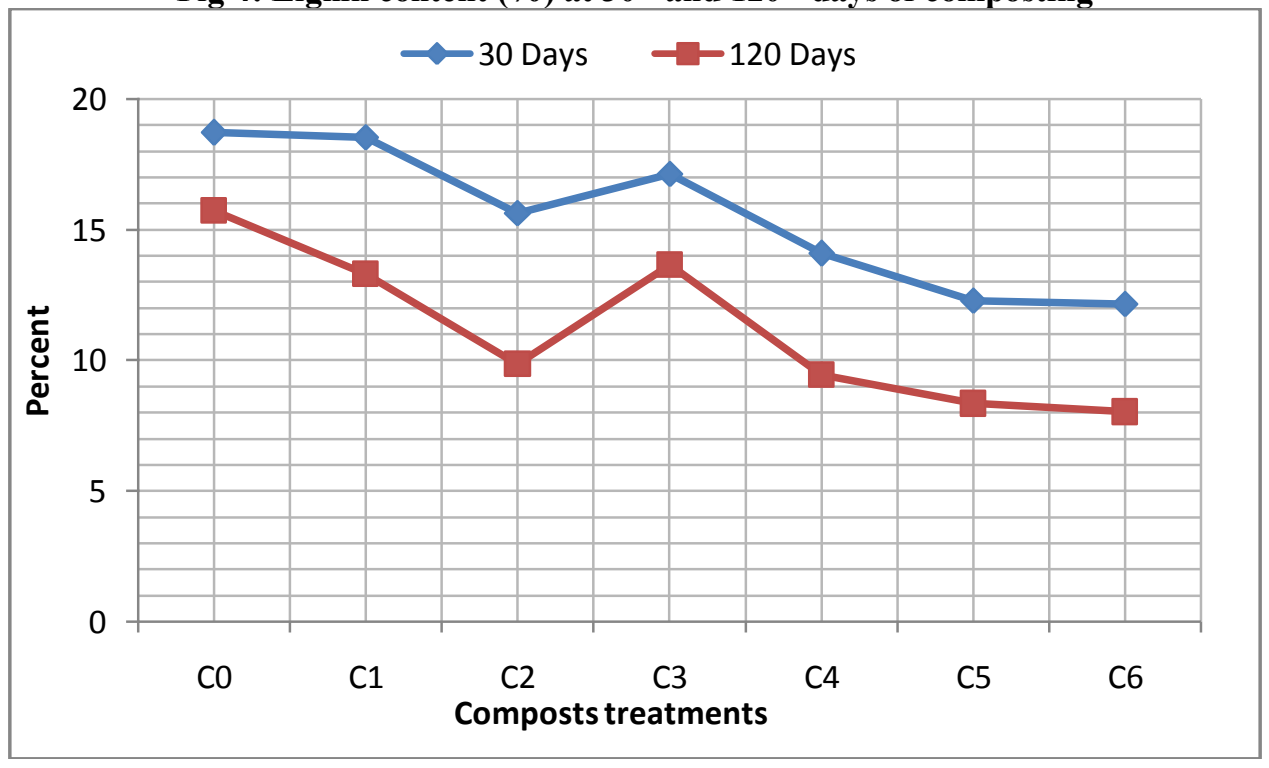

